\title{
The caries prevalence, def-t index and DMF-T index of deaf children at the primary school of special education Kota Kinabalu in Sabah
}

\author{
Mellisa May Joe, Eka Chemiawan, Jakobus Runkat \\ Department of Pediatric Dentistry Faculty of Dentistry Universitas Padjadjaran
}

\section{ABSTRACT}

Deaf is the loss of hearing partially or even totally and could happen congenitally or acquired. The purpose of this research was to find out the information of the caries prevalence, def-t and DMF-T index of Deaf children at the Primary School of Special Education in Kota Kinabalu, Sabah year 2008. This study was a description research with survey technique. All samples, 43 primary students of Primary School of Special Education in Kota Kinabalu, Sabah from kindergarten to primary six. The def-t and DMF-T index standard used the WHO criteria, namely, very low (0.1-1), low (1.2-2.6), moderate (2.7-4.4), high (4.5$6.5)$, and very high (>6.5). The results of this research indicates that the caries prevalence of the Deaf children year 2008 was $95.3 \%$. def-t index was 2.81 and DMF-T index was 1.67. The conclusion of this research was that the average def-t index included in moderate criteria and the DMF-T index was low.

Key words: Caries prevalence, def-t and DMF-T index, deaf children

\section{INTRODUCTION}

The disabled people form a substantial section of the community, and it is estimated that there are about 500 million people with disabilities worldwide. ${ }^{1}$ Children with hearing impairment constitute one of the major population groups of disabled children; about one in six hundreds neonates has congenital hearing loss. ${ }^{2}$ Hearing impairment includes children with either partial or total loss of hearing and is genetically determined in $30-70 \%$ of the cases. Remaining cases are due to prenatal causes infections like rubella or drugs during pregnancy, perinatal causes jaundice, prematurity and postnatal. Most deaf children have delayed speech development. ${ }^{3}$ Hearing aid, signlanguage and lip reading are tools for development of adequate communication abilities.

Its is obvious that deaf children have serious problems with communication and understanding which may leads to dental management problems with the dentist and child's misunderstanding about dental hygiene instructions. ${ }^{2}$ This can cause problem to routine oral hygiene care and various diseases can occur in their oral and teeth for example tooth caries. It is important for the dentist to investigate how the child communicates. It is useful to learn some basic sign language. If child lip reads, face the child and talk slowly and clearly. If the child uses sign-language, communication via the parents may be necessary. ${ }^{3}$ To facilitate communication, pictures or written descriptions are useful tools. Likewise it is valuable to learn at least a few dental related sign. 
Caries is a destructive process causing decalcification of the tooth enamel and leading to the continued destruction of enamel and dentin and cavitations of the tooth. ${ }^{4}$

According to Richard ${ }^{5}$, caries is a fermentation of dietary sugars to organic acids by micro-organisms in plaque on the tooth surface. Today, all experts on dental caries generally agree that it is an infectious and communicable disease and that multiple factors influence the initiation and progression of the disease. ${ }^{2}$

The disease is recognized to require a host; tooth in the oral environment, a dietary substrate, and aciduric bacteria. The saliva also considered a host component, the substrate, and bacteria form a biofilm; plaque that adheres to the tooth surface. Over time the presence of substrate serves as a nutrient for the bacteria, and produce acids that can demineralize the tooth. ${ }^{2}$ This caused cavitation on the tooth surface and it should be treat to prevent further destruction by restoration.

According to Bali ${ }^{6}$, prevalence of caries was very high in young people with hearing difficulties. The mean DMFT and decayed teeth in 9-12 year age group were 1.76 and 2.18 , respectively, which are higher than the general population (0.9 and 0.9), likely because of ignorance and poor oral hygiene habits. Caries prevalence in 9-12 and 13-17 year age groups was 93.33 and 88.37, respectively, being higher than the general population, likely due to ignorance on the part of parents and school teachers.

In another study conducted in Kuwait in 2001, Shyama ${ }^{7}$ demonstrated a higher prevalence of caries, $86 \%$, with a mean DMFT score of 5.0 in subjects aged 3-29 year olds with hearing impairment, due changes in lifestyle and dietary habits. In the study of Manish ${ }^{8}$, a mean DMFT score was 2.61 for 5-22 year-olds with hearing impairment, probably due to lack of parental care as parents were ignorant about dental health. This highly alarming situation needs immediate attention, a prevention-based intervention program is recommended for these special groups of subjects involving voluntary health agencies. Effort must be made to encourage the parents of these children to promote and improve their oral health.

There is no study sought to determine the oral health care knowledge and practices of a group of deaf adolescents in Malaysia, so this made the writer interested in doing research about the prevalence of caries, def-t index, and DMF-T index among deaf children at Primary School of Special Education Kota Kinabalu in Sabah.

\section{METHODS}

This research was a descriptive with survey technique. The population of this research was the deaf children at Special Education Primary School in Kota Kinabalu, Sabah. The research subjects were deaf children that study in Special Education Primary School Kota Kinabalu in Sabah. The population of this research was deaf student, kindergarten to primary six, age 5 to 13 years old. The total of the sample were 43 students. The result of the research data will be presented in tabulation. The data was collected between July and August 2007.

There were 3 students in kindergarten: primary 1 zero; primary 2 consists of 16 students; primary 3 zero; primary 4 consist of 9 students; primary 5 consists of 6 students; and primary 6 consist of 9 students. The school consists of 20 male and 23 female students at the age of 5 to 13 years old.

Equipment used are mouth mirror, explorers, cotton forceps, mask, gloves, research form, question form, pen and alcohol 70\%. Examination were performed base on research variable that is: caries; def-t; def-t index is the sum of: deciduous tooth that infected by caries (d). Note: $d$ (decay), if deciduous teeth had one or more untreated caries, but still can be treated. Deciduous tooth indicated for extraction (e). Note: e (extraction) is a deciduous teeth infected by caries that cannot restore and have to extract. Deciduous tooth that been restored (f). Note: $f$ (filled), deciduous teeth have one or more restoration that are still good. When there is no deciduous tooth during examination, it will not counted because the cause of missing are not sure whether the tooth exfoliated itself and replaced by permanent teeth or extracted due to caries. DMF-T Index is the sum of: Permanent tooth infected by caries (D) Note: D (decay), permanent tooth had one or more caries that not treated, but still can be treat. Although there are several caries on the tooth still count as 
one. Secondary caries also count one D. Permanent missing tooth or indicated to extract $(M)$. Note: $M$ (missing), tooth that have been extracted or destroy itself due to caries or tooth that have been extracted due to caries. Permanent tooth that been restored $(F)$. Note: $F$ (filled), tooth that has one or more restoration that are still good.

The steps of this research were as follows: students asked to be sited; filled students' data in the form; explained the inspection procedure to the student, helped by the teacher; do inspection and count caries, def-t and DMF-T index; students are asked to gargle and leave the examination room.

\section{Data analysis}

The obtained data were analyzed to get the result and conclusions.

Total of children that infected with caries

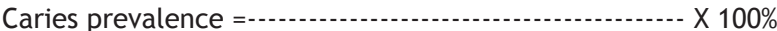

Total of children that examined

Total of def-t

def-t index $\mathrm{X} 100 \%$

Total of children that examined

Total of DMF-T

DMF-T index

Total of DMF-T
-

Total of children that examined

\section{RESULTS}

From the clinical observation, data obtain were caries prevalence, def-t and DMF-T index shown in tabulation below: Table 1 shows tooth caries prevalence of deaf children at the Primary School of Special Education in Kota Kinabalu, Sabah was $95.3 \%$.

Table 2 display the def-t index of deaf children at the Primary School of Special Education in Kota Kinabalu, Sabah were 2.81.

Table 3 display the DMF-T index of deaf children at the Primary School of Special Education in Kota Kinabalu, Sabah were 1.67.

\section{DISCUSSION}

The research result showed caries prevalence of deaf children at the Primary School
Table 1. Caries Prevalence of deaf children at the Primary School of Special Education in Kota Kinabalu, Sabah.

\begin{tabular}{ccc}
\hline $\begin{array}{c}\text { Total } \\
\text { of student }\end{array}$ & $\begin{array}{c}\text { Student with } \\
\text { caries }\end{array}$ & Percentage \\
\hline 43 & 41 & $95,3 \%$ \\
\hline
\end{tabular}

Table 2. def-t Index of deaf children at the Primary School of Special Education in Kota Kinabalu, Sabah.

\begin{tabular}{cccccc}
\hline d & e & f & def & Total of student & Index \\
\hline 43 & 42 & 36 & 121 & 43 & 2.81 \\
\hline
\end{tabular}

Table 3. DMF-T Index of deaf children at the Primary School of Special Education in Kota Kinabalu, Sabah.

\begin{tabular}{cccccc}
\hline D & M & F & DMF & Total of student & Index \\
\hline 41 & 15 & 16 & 72 & 43 & 1.67 \\
\hline
\end{tabular}

of Special Education in Kota Kinabalu, Sabah was very high and DMF-T index were 1.67. According to World Health Organization, the classification. standard degree of tooth caries of this research was low (1.2-2.6), This is like due to frequency of tooth brushing. Ling Zhu mention that frequency of tooth brushing has impact on dental caries experience. Result of the questioner shows that $51.2 \%$ of student brush their teeth twice a day, but $58.1 \%$ student brush their teeth on only during bathing. According to Harris ${ }^{10}$, children are more likely to be caries free if their teeth are brushed from an early age, twice daily with fluoride toothpaste after eating and before sleeping.

Brushing and other aid example, flossing can remove and prevent the formation of plaque. Result of the questioner shows that $79 \%$ student did not use any aid to clean their teeth. Fifty eight point one percent of student brush their teeth with combination of vertical and horizontal movement and $62 \%$ students brush all surfaces of their teeth.

Children like to eat sweets or candy and chocolate. That kind of food consist large amount of sucrose. Sucrose includes cariogenic substance. Minimizing consumption of cariogenic substance is one of the efforts to prevent formation of caries, and brushing teeth after meals is recommended. ${ }^{1}$ Thirty nine point five percent students admit they like to eat sweets and $60.5 \%$ of student did not rinse their teeth after consuming sweets. 
Questioner results show that $60.5 \%$ students have experience toothache and $97.6 \%$ students experience toothache due to tooth decay or cavity. To relieve the pain, $86 \%$ students went to visit the dentist. Dental caries is a disease that damages tooth structures, resulting in what is commonly called tooth decay or cavity, which is a hole in the teeth. This damage first affects the hard tissues of the teeth (enamel, dentin and cementum). As the destruction progresses, these tissues begin to break down, which can eventually lead to holes in the teeth. If left untreated, the disease can lead to pain, tooth loss and infection. Visit the dentist to preserve tooth structures and prevent further destruction of the tooth. The treatment for dental caries, dentist perform indicated treatment depend on the case, for example dental restoration, root canal therapy, and extraction. ${ }^{12}$

The questioner result showed that $72.1 \%$ students visited the dentist more than 1 year ago. The frequency of student went to dentist if toothache occurred was $79 \%$ student. To maintain a good oral hygiene or to prevent dental caries, visit the dentist minimally twice a year even though there is no toothache ${ }^{13}$, but there were $37.2 \%$ student seldom go to dentist because of no toothache.

Oral health education models have dominated the majority of caries prevention strategies. Oral health information may have modified or improved the health behavior of children. ${ }^{14}$ About $72.1 \%$ students never joined oral health program beside at the school.

The result of research shows that def-t index of deaf children at the Primary School of Special Education in Kota Kinabalu, Sabah were 2.81. This result obtained from the deciduous teeth that have caries, extracted and restored. According to WHO classification this categorize moderate high (2.7-4.4).

Oral health care can be supported by self motivation. Oral hygiene educations have given emphasis to prevent oral care in order to improve oral health behaviour. The responses concerning treatment for deaf children oral have to focus and improved as in quality so they can achieve good oral hygiene optimally. ${ }^{13}$

\section{CONCLUSION}

The prevalence caries of deaf children at the Primary School of Special Education in Kota Kinabalu, Sabah was very high. Whereas def-t index was moderate high and DMF-T was low.

\section{REFERENCES}

1. Barriers WN. Discrimination and prejudice. In: Disability and oral care. London: Nune JHed, FDI World Dent Press; 2000. p. 15-20.

2. MCDonald RE, Avery DR, Dean JA. Dentistry for the child and adolescents. $8^{\text {th }}$ ed. St. Louis: Mosby Co.; 2004. p. 548.

3. Goran K, Sven P. Pediatric dentistry. In: A Clinical approach. $1^{\text {st }}$ ed. Copenhagen: Munksgaard; 2001. p. 455-6.

4. Dorland Pocket medical edition. W.B. Saunders; 2001.

5. Welbury RR. Pediatric dentistry. $2^{\text {nd }}$ ed. New York: Oxford University Press; 2001. p. 95.

6. Bali RK. National oral health survey and fluoride mapping 2002-2003 in Rajasthan. New Delhi: Dent Council of India; 2004. p. 96.

7. Shyama M. Fundamentals of operative dentistry. In: A contemporary approach. Chicago: Quintessence Publishing Co., Inc.; 2001. p. 70-80.

8. Manish J. Dentition status and treatment needs among children with impaired hearing attending a special school for the deaf and mute in Udaipur, India. J Oral Science 2008; 50(2):161-5.

9. Ling Z. Oral health knowledge, attitudes and behavior of children and adolescent in China. Int Dent J 2003:289-98.

10. Harris. Risk factors for dental caries in young children: a systematic review of the literature. Com Dent Health 2004:71-85.

11. Samuel B. Medical microbiology. $4^{\text {th }}$ ed. London: A Harcourt Health Sciences Co.; 2001. p. 67,103 .

12. Wikimedia foundation. Dental caries. Inc., U.S registered $501^{\circ}$ (3) tax-deductible nonprofit charity. 2008. [cited 2008 September 24]. Available from: http;//www. 
wikimediafoundation.org.

13. Yenny L. The caries prevalence, def-t index and DMF-T index of deaf children at the special school (SLB-B) Minor thesis. Bandung:
Faculty of Dentistry Universitas Padjadjaran; 2005. p. 41.

14. Quteish T. Oral health in Jordan. Int Dent J 2004:395-400. 